\title{
Dosing Time Matters
}

Marc D. Ruben ${ }^{1}$, David F. Smith ${ }^{2,3}$, Garret A. FitzGerald ${ }^{4,5,6}$, and John B. Hogenesch ${ }^{1 *}$

${ }^{1}$ Division of Human Genetics, Center for Chronobiology, Department of Pediatrics, Cincinnati Children's Hospital Medical Center, 240 Albert Sabin Way, Cincinnati, OH, 45229

${ }^{2}$ Divisions of Pediatric Otolaryngology and Pulmonary and Sleep Medicine, Cincinnati Children's Hospital Medical Center, 3333 Burnet Ave, Cincinnati, OH 45229

${ }^{3}$ Department of Otolaryngology-Head and Neck Surgery, University of Cincinnati School of Medicine, 231 Albert Sabin Way, Cincinnati, OH, 45267

${ }^{4}$ Department of Systems Pharmacology and Translational Therapeutics, at the University of Pennsylvania Perelman School of Medicine, Philadelphia, PA 19104 USA

${ }^{5}$ Department of Medicine, at the University of Pennsylvania Perelman School of Medicine, Philadelphia, PA 19104 USA

${ }^{6}$ Institute for Translational Medicine and Therapeutics (ITMAT), at the University of Pennsylvania Perelman School of Medicine, Philadelphia, PA 19104 USA

${ }^{*}$ Corresponding Author. Email: john.hogenesch@cchmc.org

\section{Abstract}

Trainees in medicine are taught to diagnose and administer treatment as needed; time-of-day is rarely considered. Yet accumulating evidence shows that $\sim$ half of human genes and physiologic functions follow daily rhythms. Circadian medicine aims to incorporate knowledge of these rhythms to enhance diagnosis and treatment. Interest in this approach goes back at least six decades, but the path to the clinic has been marked by starts, stops, and ambiguity. How do we move the field forward to impact clinical practice? To gain insight into successful strategies, we studied the results of more than 100 human trials that evaluated time-of-administration of drugs. 


\section{Introduction}

Trainees in medicine are taught to diagnose and administer treatment as needed; time-of-day is rarely considered. Yet a wealth of accumulating evidence shows that molecular clocks orchestrate $24 \mathrm{~h}$ rhythms in vital cardio-metabolic, endocrine, immunologic, and behavioral functions. Half of the mammalian protein-coding genome is expressed with a circadian rhythm $(1,2)$. Time, therefore, adds a potentially important dimension to medicine.

Circadian medicine aims to incorporate knowledge of $24 \mathrm{~h}$ biological rhythms to enhance diagnosis and treatment. There are two broad strategies: 1) target the molecular clock, or 2) exploit its rhythmic outputs. In the former, the therapeutic target is the molecular oscillator itself. Light therapy for sleep disorders is the hallmark example, but feeding (3), exercise, and drugs $(4,5)$ can also modulate the clock to potentially influence health $(4)$. Our research focuses on the latter strategy - timing the delivery of treatment to coincide with rhythmic outputs of the clock. Interest in this approach goes back at least six decades (6), but the path to the clinic has been marked by starts, stops, and ambiguity. A series of recent insights, however, has renewed clinical interest.

Here, we discuss how current technology is shaping circadian medicine. Based on an analysis of more than 100 human studies, we provide recommendations for future trials in circadian medicine.

\section{Starts, stops, and scope}

Fifty years ago, Shapiro and Rodwell showed that the rate-limiting enzyme in cholesterol synthesis oscillates with a $24 \mathrm{~h}$ period in rat liver $(7,8)$. Fast-forward twenty years, and simvastatin - a short-acting inhibitor of this enzyme - was approved for the treatment of hyperlipidemia, labeled to take it "once a day in the evening". This marked the first translation from knowledge of a circadian mechanism to a widely used medication. 
In retrospect, simvastatin might have foreshadowed a wave of circadian drug development across therapeutic areas. It did not. Although studies in the mid-1990's showed that rhythmically delivered chemotherapy could reduce toxicity in colorectal cancer (9-11), they did not lead to changes in FDA labeling, treatment guidelines, or standard of practice. Trials in a handful of other therapeutic areas around this time also supported time-dependent-dosing (12-16), with similarly limited influence. In fact, there are few examples of mechanism-based circadian medicine. Only 4 of the 50 currently most prescribed drugs (17) have FDA-labeled time-of-day dosing recommendation. The $20^{\text {th }}$ World Health Organization's Model List of Essential Medicines makes no mention of dosing time.

\section{NEW DISCOVERIES RENEW CLINICAL INTEREST}

Accumulating data show circadian regulation at genomic and physiologic levels that is far more extensive than previously understood. The central clock in the hypothalamus coordinates rhythmic behavior. However, local clocks exist in virtually every peripheral tissue in mammals (18). In a high-resolution time-series study of twelve mouse organs, nearly half of protein-coding genes were expressed with a $24 \mathrm{~h}$ rhythm in at least one organ (1). These clock-driven rhythms in gene expression generate rhythms in hormone secretion, lipid and glucose metabolism, lung and cardiovascular physiology, and many other tissue-specific functions (19). Remote sensors and wearable technology have revolutionized data collection from humans "in the wild." Using multiple devices, a small feasibility study uncovered daily variation in $62 \%$ of physiologic and behavioral measures from 6 healthy individuals (20).

Expression of many disease phenotypes is also time-dependent. The incidence of heart attacks, and symptoms in asthma, allergic rhinitis, cancer, arthritis, depression and suicidal intent, peptic ulcers, and pain all show time-of-day variation (21). Thousands of rhythmically-expressed genes metabolize, transport, or are the targets of drugs $(1,22)$. For drugs with rapid pharmacokinetics $(P K)$, circadian time could influence efficacy and/or toxicity and thus, their therapeutic index (23). 


\section{HARMONIZING TREATMENT WITH MOLECULAR RHYTHMS}

Animal experiments are defining different ways to leverage circadian time for therapeutic benefit. Timing the administration of a drug to coincide with peak levels of its physiologic target was effective in models of atherosclerosis (24) and obesity (25), to name a few. Alternatively, drug delivery can be timed to coincide with trough levels of an undesired target, successfully executed in a mouse model of pancreatic cancer (26). Another approach is to harmonize the administration of a drug with rhythms in its absorption, distribution, metabolism, or excretion. Recent work identified a $24 \mathrm{~h}$ rhythm in blood-brain barrier (BBB) permeability that influences efficacy of an antiepileptic drug in a Drosophila model of seizure (27).

All of this has generated renewed enthusiasm for circadian time as a parameter in medicine; in 2018 alone, 15 reviews were published with "chronotherapy" in the title/abstract. But how do we move the field forward to influence clinical practice? To gain insight into successful strategies, we studied the results of 106 trials that evaluated time-of-administration of drugs.

\section{0 years of clinical trials - an analysis}

We identified human trials where time-of-day drug administration was the specific point of investigation (Fig. 1 and Table S1). Our criteria were published studies that directly compared at least two different time-of-day treatment schedules and measured efficacy or toxicity.

Altogether, these studies comprised 70 distinct drugs or combinations or medical procedures across 15 different therapeutic areas.

\section{A TRACK-RECORD OF SUCCESS IN HIGHLY PREVALENT DISEASES}

$75 \%$ of trials $(78 / 105)$ found that treatment efficacy or toxicity depended on dosing time (Fig $1 \mathrm{~A})$. Collectively, the work provides substantial support for circadian medicine in hypertension, cancer, asthma, and arthritis - diseases with extraordinarily high prevalence and unmet medical need (Fig 1B and fig S1). The number and size of trials in these areas has increased over the past several decades, reflecting well-known $24 \mathrm{~h}$ patterns in their phenotypic severity. 
Nevertheless, there are dozens of other indications (many with circadian components) and thousands of other approved drugs where the impact of time-of-day is unexplored.

\section{PHARMACOKINETICS MATTER, IN UNEXPECTED WAYS}

Pharmacokinetics suggest that only drugs with half-lives of $\sim 6 \mathrm{~h}$ or less would show time-of-day dependencies. Strikingly, our analysis shows that the majority of drugs with half-lives as long as 8-15 h were influenced by dosing-time (Fig 1C). This suggests that many commonly used drugs have narrow therapeutic windows and are influenced by dosing time.

The relationship described in Fig $1 \mathrm{C}$ helps to reconcile seemingly inconsistent trial results, even for drugs of the same class. For example, whereas short-acting simvastatin (half-life $3 \mathrm{~h}$ ) was consistently more effective when taken in the evening (28-31), neither long-acting atorvastatin $(32,33)$ (half-life $25 \mathrm{~h})$ nor extended-release simvastatin $(34,35)$ showed morning-evening differences in the majority of trials (fig S1). Long-acting formulations likely obscured circadian effects in other areas as well. Amolidipine, a long-acting $\mathrm{Ca}^{2+}$ channel blocker (half-life $40 \mathrm{~h}$ ), did not lower blood pressure (BP) in a time-dependent manner $(36,37)$. However, when it was combined with a short-acting angiotensin receptor blocker (valsartan or olmesartan) $(38,39)$ or a diuretic (40), evening was more effective than morning dosing (fig S1).

Overall, 57 of $67(85 \%)$ trials with half-lives $<15$ h showed dosing time-dependence compared to just 9 of $23(39 \%)$ for longer-acting drugs. This information could be the difference in an FDA approval.

\section{SMALL TRIALS AND TOO FEW TIME POINTS}

There are still a number of discrepancies that cannot be explained by differences in drug kinetics (fig S1). Limitations in study design may contribute to this. Many of the trials were small. Median enrollment in the hypertension studies, for example, was 62 subjects, with only one study including more than 500 patients. By comparison, the most recently FDA-approved antihypertensive (Byvalson) was based on a pivotal trial of 4,161 hypertensives (41). This trial 
did not test for time-dependency. One of the components, valsartan, has a short half-life and established time-dependent efficacy (42-44).

Further, these studies were underpowered to detect periodic effects. The vast majority ( 90\%) compared only two time points, almost always morning versus evening, which might miss circadian effects at other times of day. Lastly, most studies did not account for possible interindividual variability in internal circadian phase, arising from differences in lifestyle, work schedule, or chronotype. 8AM on the wall clock is not "morning" for everyone.

Despite these limitations, there is significant support for circadian medicine. Yet, a major barrier to clinical translation has been the lack of understanding of how the circadian clock governs human physiology and pathophysiology. Even for medicines with demonstrable dosing-time-dependent effects, the mechanisms are not well defined.

\section{Present: towards mechanism-driven circadian medicine}

\section{MAPPING DYNAMIC DRUG TARGETS IN HUMANS}

Human time-series data have not been possible at the spatial and temporal resolution of animal models (45-47). Although longitudinal studies detected rhythmic gene expression from human samples (48-52), taking multiple biopsies from a patient over a $24 \mathrm{~h}$ period is difficult to execute, costly, and limited to the most easily accessible tissues. Alternatively, population-scale rhythms can be detected from single donor samples (53); however, time of sample collection is often not recorded. An algorithm called CYCLOPS was developed to reconstruct sample order in the absence of sample collection times (26).

CYCLOPS was used to build a first population-scale human atlas of circadian gene expression (2) and showed that regardless of a person's sex, age, or ethnicity, the body's internal clock regulates half of the protein-coding genome. This work connected thousands of different drugs both investigational and approved - to thousands of cycling genes that encode drug targets, 
transporters, or metabolizing enzymes. This identified many specific mechanisms by which time-of-day might influence drug activity.

\section{TIME FOR STANDARD-OF-CARE THERAPIES}

Genes that encode targets of antihypertensives cycle in the human cardiovascular system (2). These drugs are influenced by time of administration (Fig 1, fig S1). With knowledge of the where and when of drug target abundance, researchers and developers can make predictions about the influence of timed-dosing of many routinely prescribed short-acting medications.

Current knowledge might also help mitigate drug-related toxicity. Cardiotoxicity is the leading cause of drug discontinuation at all stages (54). Many drug classes, while not necessarily indicated for cardiovascular disease, actively target the heart and peripheral vasculature. For example, theophyllines - bronchodilators administered for pulmonary disease - function by inhibiting genes that are also critical to normal heart function (55-57). We now know that several of these "off-targets" are rhythmically expressed in human heart and vasculature (2). Can dosage time for these and other compounds be leveraged to reduce cardiotoxicity?

Time matters for several non-drug interventions as well. At least eight separate trials have shown that radiation therapy is less toxic when administered at a particular time (fig S1), thought to be when non-tumor cells are less susceptible to radiation damage (58). Circadian-dependent vulnerability to injury also exists in the context of cardiovascular procedures $(59,60)$. Even with this understanding, practical limitations make implementation of timed-therapy difficult. Despite substantial support for timed administration of chemotherapy, this is not standard of practice due to multiple barriers (i.e. scheduling infusions at specific times and limited infrastructure).

\section{Future: drug development to drive circadian medicine}

Ultimately, trials in circadian medicine will need to demonstrate an unambiguous health benefit over standard-of-care. Based on analysis of an $\sim 50$ year history of more than 100 clinical trials, we offer a set of recommendations for future studies in circadian medicine. 
Genome-scale maps of $24 \mathrm{~h}$ rhythms are providing volumes of data for hypothesis-driven circadian medicine. There are $\sim 2,000$ approved drugs. Those whose targets oscillate in humans are a good place to start. Still, the best targets and times for treatment in the context of disease need to be determined empirically. The most effective medicines, we suspect, will incorporate knowledge of $24 \mathrm{~h}$ dynamics in both health and disease.

\section{SHORTER-ACTING AGENTS}

Since the majority of support for circadian medicine comes from trials of drugs with half-lives < $15 \mathrm{~h}$, we suggest that future efforts focus there. Although some very long-acting agents showed administration-time-dependent effects (fig S1, Table 1), the mechanisms are unclear. Trials should strive to delineate drug PK, ideally at more than one dosage time.

The industry trend towards sustained-release formulations, while good for patient adherence, can be problematic from the vantage of circadian biology. Drug exposure is constant over $24 \mathrm{~h}$ but its target(s) may not be. Further, flattening a process that is normally rhythmic may be maladaptive. For example, in people with high BP, short-acting antihypertensives were more effective than long-acting forms at restoring the normal nighttime drop in BP (61) - which may improve cardiovascular outcomes (62).

\section{BEYOND MORNING VERSUS EVENING}

The simplest comparison, between morning and evening dosing (91 of 105 trials), can only confirm or rule out a difference between these two times. Although medications are typically taken at these times for convenience, other times may be more effective or safe. For drugs with short half-lives, two-time point sampling is likely insufficient. While the gold standard of hourly sampling for genome-scale circadian analysis (63) may be impractical for human trials, clinical researchers should nevertheless weigh the upstream cost of additional time-points against the downstream cost of a type II error. 
Trials in circadian medicine must control for interpersonal differences in phase. At a minimum, subject's rest-activity rhythms provide a reasonable estimate of internal circadian phase. Recently, three independent studies reported algorithms capable of inferring circadian phase from skin $(64)$ or blood samples $(65,66)$. These pave the way for development of biomarkers to help optimize the delivery time of treatment for patients where determining circadian phase may be difficult (e.g. patients in an ICU).

\section{CONTROL FOR CIRCADIAN DISRUPTION}

Many of the trials we studied were conducted in artificial environments. Subjects in inpatient care settings - often detached from natural environmental fluctuations for extended periods of time - are at risk for circadian disruption. Simply recreating changes in natural light over 24 hours improved recovery in experimental (67) and hospital-based clinical studies (68-70). Besides light, noise levels and frequent awakenings are also sources of circadian disruption. This becomes a critical consideration for time-of-day effects and is leading many to rethink hospital layouts from the vantage of circadian biology.

\section{Conclusions}

The most commonly prescribed drugs help only a minority of patients who take them (71). Although the common refrain to this is a call for better genetic precision, circadian effect sizes can be just as large. Circadian precision medicine aims to deliver treatment in harmony with target physiology and has shown that it can improve efficacy and safety in many feasibility-sized trials in hypertension, arthritis, asthma, and cancer, among others. Recent technological advances in circadian biology have the potential to exert broad influence on medical practice.

At the time of this review, there is one registered clinical trial in the United States with time-of-day endpoints: Temozolomide Chronotherapy for High Grade Glioma (72). Will circadian biology factor into the future of treatment? Time will tell. 
Fig 1. Circadian medicine is accelerating and has a track-record of success in highly prevalent diseases. (A) $75 \%$ of clinical trials (78/105) showed dosing-time-dependent efficacy or toxicity. (B) Numbers of trials by therapeutic area. Detailed information on drug type, half-life, and outcome for each trial shown in fig S1. (C) The relationship between drug half-life and time-of-day effect. Trials were grouped by drug half-life, with roughly equal numbers of trials in each group. For trials of combination therapies, we considered the drug ingredient with the shortest half-life.
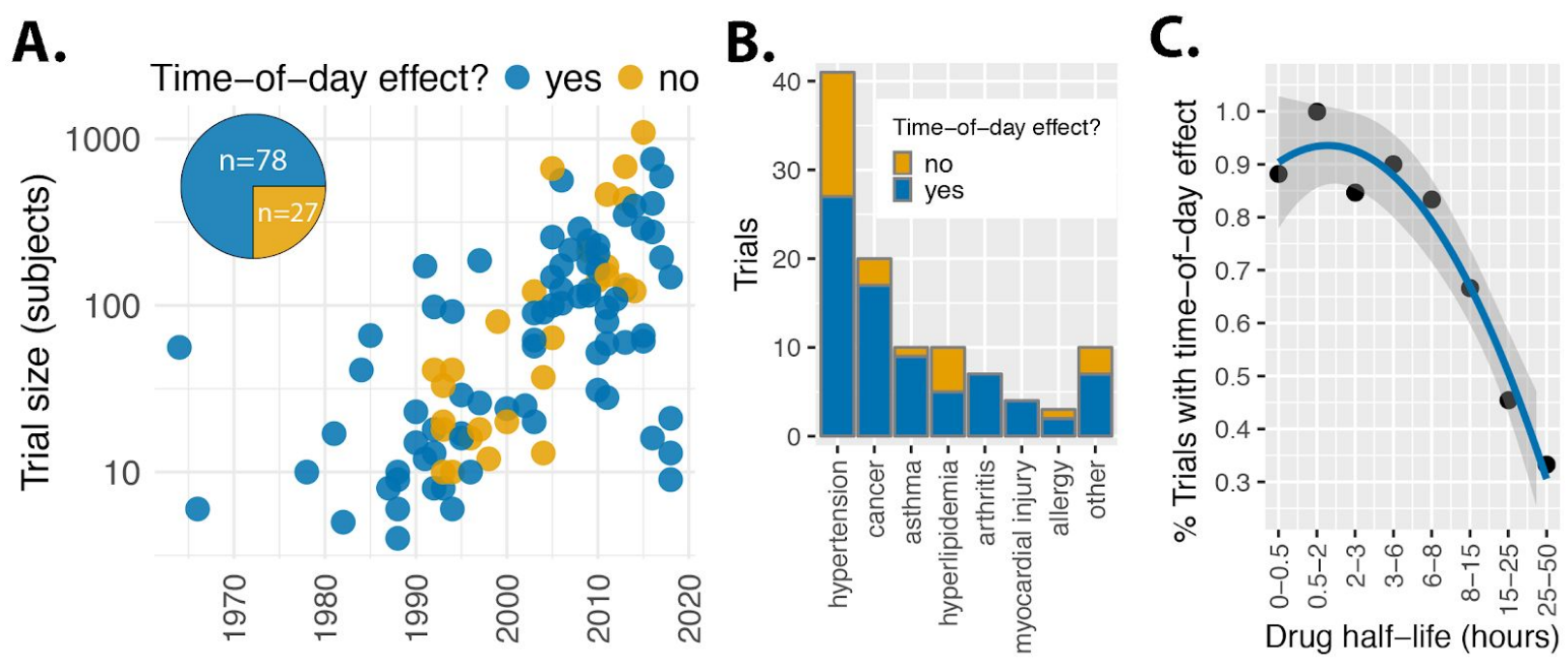
bioRxiv preprint doi: https://doi.org/101101/570119; this version posted March 21, 2019. The copyright holder for this preprint (which was not

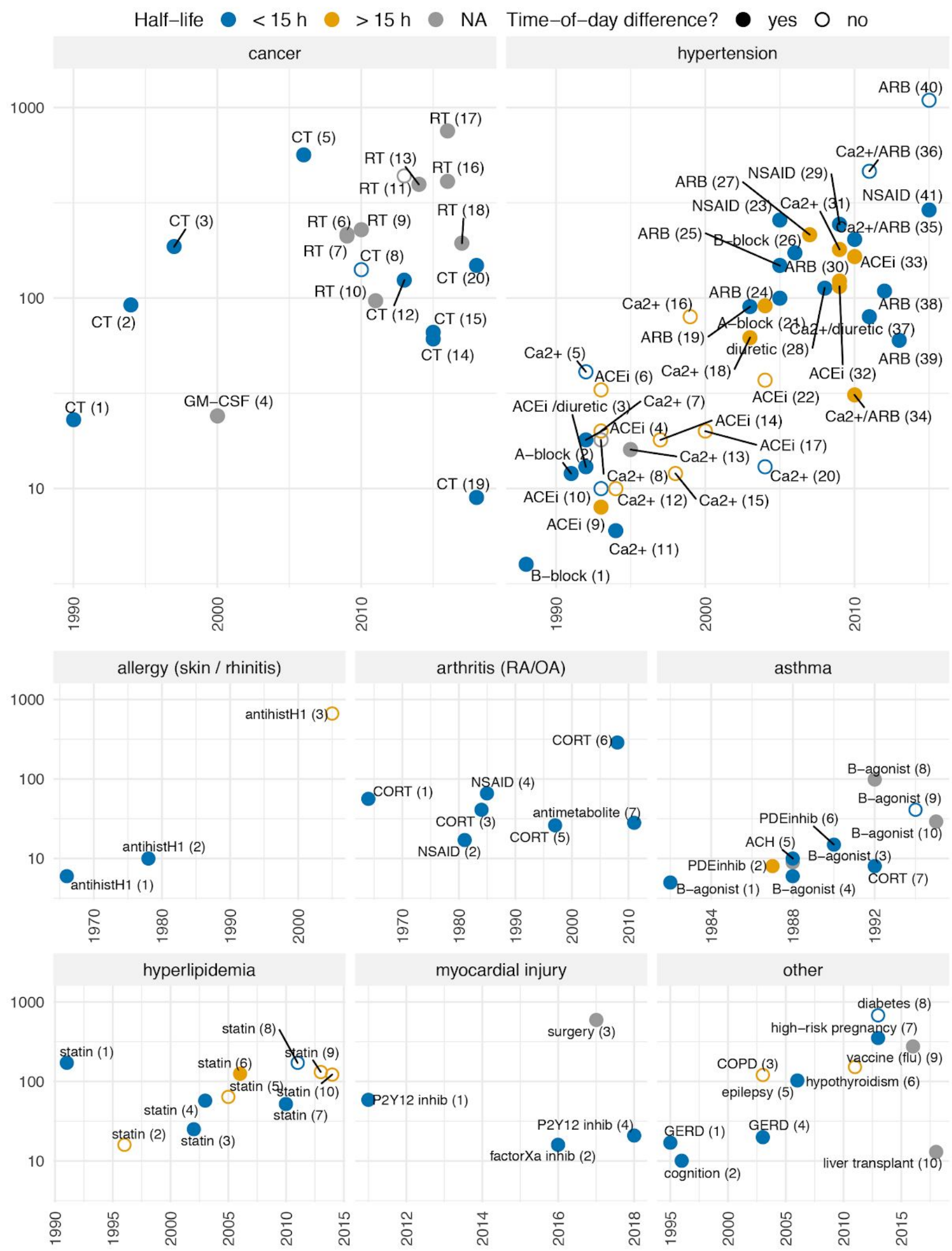


fig S1. 50 years of clinical studies testing dosing-time-dependence of medical treatment. 105 clinical studies that were: 1) published, 2) directly compared at least two different time-of-day treatment schedules, and 3) measured clinical effect or toxicity. Point color indicates drug half-life: short $(\leq 15 \mathrm{~h})$, long $(>15 \mathrm{~h})$, or unknown (NA). Point fill distinguishes trials that found significant $(P$-value $<0.05$ ) administration-time-dependent efficacy and/or toxicity (solid) from trials that did not (empty). Trials grouped by therapeutic area and labeled according to drug class. Study citations are indicated by the number in parentheses for each trial (table S1). 
bioRxiv preprint doi: https://doi.org/10.1101/570119; this version posted March 21, 2019. The copyright holder for this preprint (which was not certified by peer review) is the author/funder, who has granted bioRxiv a license to display the preprint in perpetuity. It is made available under aCC-BY-NC-ND 4.0 International license.

\begin{tabular}{|c|c|c|c|c|c|c|}
\hline Group & Specific TA & Trial & Drug & Class & Half-life $^{\star}(\mathrm{hr})$ & Ref. \\
\hline \multirow[t]{3}{*}{ Allergy } & skin & 1 & cyproheptadine & antihistamine $\mathrm{H} 1$ & 8 & $(73)$ \\
\hline & skin & 2 & terfenadine & antihistamine $\mathrm{H} 1$ & 3.5 & $(74)$ \\
\hline & rhinitis & 3 & desloratadine & antihistamine $\mathrm{H} 1$ & 50 & (75) \\
\hline \multirow[t]{7}{*}{ Arthritis } & RA & 1 & prednisone & corticosteroid & 2.5 & $(76)$ \\
\hline & RA & 2 & flurbiprofen & NSAID & 5 & $(77)$ \\
\hline & RA & 3 & prednisone & corticosteroid & 2.5 & $(78)$ \\
\hline & $\mathrm{OA}$ & 4 & indomethacin & NSAID & 4.5 & $(79)$ \\
\hline & RA & 5 & prednisone & corticosteroid & 2.5 & $(80)$ \\
\hline & RA & 6 & prednisone & corticosteroid & 2.5 & $(81)$ \\
\hline & RA & 7 & methotrexate & antimetabolite & 6 & $(82)$ \\
\hline \multirow[t]{10}{*}{ Asthma } & asthma & 1 & epinephrine & beta-adrenergic antagonist & 0.5 & $(83)$ \\
\hline & asthma & 2 & theophylline sustained release & PDE inhib + adenosineR antagonist & 24 & $(84)$ \\
\hline & asthma & 3 & terbutaline-sustained release & beta-adrenergic antagonist & n/a & $(85)$ \\
\hline & asthma & 4 & orciprenaline & beta-adrenergic antagonist & 6 & $(86)$ \\
\hline & asthma & 5 & atropine & anticholinergic & 3 & $(87)$ \\
\hline & asthma & 6 & theophylline & PDE inhib + adenosineR antagonist & 8 & (13) \\
\hline & asthma & 7 & prednisone & corticosteroid & 2.5 & $(88)$ \\
\hline & asthma & 8 & albuterol sustained release & beta-adrenergic antagonist & n/a & $(89)$ \\
\hline & asthma & 9 & salmeterol & beta-adrenergic antagonist & 5.5 & $(90)$ \\
\hline & asthma & 10 & tulobuterol & beta-adrenergic antagonist & n/a & $(91)$ \\
\hline \multirow[t]{19}{*}{ Cancer } & breast carcinoma, HCC, bile duct & 1 & L-OHP & CT & 0.5 & $(9)$ \\
\hline & colorectal & 2 & L-OHP + 5-FU + FA & CT & 0.5 & $(10)$ \\
\hline & colorectal & 3 & $\mathrm{~L}-\mathrm{OHP}+5-\mathrm{FU}+\mathrm{FA}$ & CT & 0.5 & $(11)$ \\
\hline & soft tissue/bone sarcoma & 4 & GM-CSF & GM-CSF & $\mathrm{n} / \mathrm{a}$ & $(92)$ \\
\hline & colorectal & 5 & L-OHP + 5-FU + FA & CT & 0.5 & $(93)$ \\
\hline & head and neck & 6 & radiotherapy & RT & $\mathrm{n} / \mathrm{a}$ & $(94)$ \\
\hline & head and neck & 7 & radiotherapy & RT & $\mathrm{n} / \mathrm{a}$ & $(58)$ \\
\hline & metastatic colorectal & 8 & L-OHP + capacitabine & CT & 0.5 & $(95)$ \\
\hline & cervical carcinoma & 9 & radiotherapy & RT & $\mathrm{n} / \mathrm{a}$ & $(96)$ \\
\hline & brain metastasis in NSCLC & 10 & radiotherapy-gamma knife & RT & $\mathrm{n} / \mathrm{a}$ & $(97)$ \\
\hline & brain metastasis in NSCLC & 11 & radiotherapy-stereotactic (SRS) & RT & $\mathrm{n} / \mathrm{a}$ & $(98)$ \\
\hline & advanced NPC & 12 & $5-F U+D D C$ & CT & 0.5 & (99) \\
\hline & breast cancer & 13 & radiotherapy & RT & n/a & $(100)$ \\
\hline & NSCLC & 14 & DDC & CT & 0.5 & $(101)$ \\
\hline & locally advanced NPC & 15 & $\mathrm{DOC}+\mathrm{DDC}+5-\mathrm{FU}$ & CT & 0.5 & $(102)$ \\
\hline & prostate adenocarcinoma & 16 & radiotherapy & RT & $\mathrm{n} / \mathrm{a}$ & (103) \\
\hline & multiple brain metastases & 17 & radiotherapy & RT & $\mathrm{n} / \mathrm{a}$ & (104) \\
\hline & painful bone metastases & 18 & radiotherapy & RT & $\mathrm{n} / \mathrm{a}$ & (105) \\
\hline & oral squamous cell carcinoma & 19 & $\mathrm{DOC}+\mathrm{DDC}+5-\mathrm{FU}$ & CT & 0.5 & $(106)$ \\
\hline
\end{tabular}


bioRxiv preprint doi: https://doi.org/10.1101/570119; this version posted March 21, 2019. The copyright holder for this preprint (which was not certified by peer review) is the author/funder, who has granted bioRxiv a license to display the preprint in perpetuity. It is made available under aCC-BY-NC-ND 4.0 International license.

\begin{tabular}{|c|c|c|c|c|c|c|}
\hline & locoregionally advanced NPC & 20 & DDC & CT & 0.5 & (107) \\
\hline \multirow[t]{10}{*}{ Hyperlipidemia } & hyperlipidemia & 1 & simvastatin & statin & 3 & $(28)$ \\
\hline & hyperlipidemia & 2 & atorvastatin & statin & 25 & (32) \\
\hline & hyperlipidemia & 3 & simvastatin & statin & 3 & $(29)$ \\
\hline & hyperlipidemia & 4 & simvastatin & statin & 3 & $(30)$ \\
\hline & hyperlipidemia & 5 & atorvastatin & statin & 25 & (33) \\
\hline & hyperlipidemia & 6 & atorvastatin & statin & 25 & $(108)$ \\
\hline & hyperlipidemia & 7 & simvastatin & statin & 3 & (31) \\
\hline & hyperlipidemia & 8 & simvastatin, ezetimibe & statin, azetidine & 3 & $(109)$ \\
\hline & hyperlipidemia & 9 & simvastatin-ER & statin & 22 & (34) \\
\hline & hyperlipidemia & 10 & simvastatin-ER & statin & 22 & (35) \\
\hline \multirow[t]{30}{*}{ Hypertension } & hypertension & 1 & propanalol & beta-adrenergic antagonist & 4 & $(110)$ \\
\hline & hypertension & 2 & phenatolamine & alpha-adrenergic antagonist & 0.3 & $(111)$ \\
\hline & hypertension & 3 & captopril, hydrochlorothiazide & ACE-inhibitor, diuretic & 2 & $(15)$ \\
\hline & hypertension & 4 & quinapril & ACE-inhibitor & 3 & $(16)$ \\
\hline & hypertension & 5 & nitrendipine & Ca2+-channel blocker & 12 & $(112)$ \\
\hline & hypertension & 6 & ramipril & ACE-inhibitor & 24 & $(113)$ \\
\hline & hypertension & 7 & amlodipine & Ca2+-channel blocker & 40 & $(36)$ \\
\hline & hypertension & 8 & isradipine-ER & Ca2+-channel blocker & n/a & $(114)$ \\
\hline & hypertension & 9 & enalapril & ACE-inhibitor & 35 & $(115)$ \\
\hline & hypertension & 10 & benazepril & ACE-inhibitor & 10.5 & $(116)$ \\
\hline & hypertension & 11 & nitrendipine & Ca2+-channel blocker & 12 & $(117)$ \\
\hline & hypertension & 12 & nifedipine-ER & Ca2+-channel blocker & 24 & $(118)$ \\
\hline & hypertension & 13 & isradipine-ER & Ca2+-channel blocker & n/a & $(119)$ \\
\hline & hypertension & 14 & perindopril & ACE-inhibitor & 30 & $(120)$ \\
\hline & hypertension & 15 & amlodipine & Ca2+-channel blocker & 40 & (37) \\
\hline & hypertension & 16 & nislodipine-ER & Ca2+-channel blocker & 14 & $(121)$ \\
\hline & hypertension & 17 & imidapril & ACE-inhibitor & 15 & $(122)$ \\
\hline & hypertension & 18 & amlodipine & Ca2+-channel blocker & 40 & $(123)$ \\
\hline & hypertension & 19 & valsartan & ARB & 7 & $(42)$ \\
\hline & hypertension & 20 & cilnidipine & Ca2+-channel blocker & 0.3 & $(124)$ \\
\hline & hypertension & 21 & doxazosin-ER & alpha-adrenergic antagonist & 22 & $(125)$ \\
\hline & hypertension & 22 & trandolapril & ACE-inhibitor & 24 & $(126)$ \\
\hline & hypertension & 23 & aspirin & NSAID & 1 & (127) \\
\hline & hypertension & 24 & valsartan & ARB & 7 & $(128)$ \\
\hline & hypertension & 25 & valsartan & ARB & 7 & (43) \\
\hline & hypertension & 26 & nebivolol & beta-adrenergic antagonist & 10 & $(129)$ \\
\hline & hypertension & 27 & telmisartan & ARB & 24 & $(130)$ \\
\hline & hypertension & 28 & torasemide & diuretic & 3.5 & $(131)$ \\
\hline & hypertension & 29 & aspirin & NSAID & 1 & $(132)$ \\
\hline & hypertension & 30 & olmesartan & ARB & 13 & (133) \\
\hline
\end{tabular}




\begin{tabular}{|c|c|c|c|c|c|c|}
\hline & hypertension & 31 & nifedipine-ER & Ca2+-channel blocker & 24 & $(134)$ \\
\hline & hypertension & 32 & ramipril & ACE-inhibitor & 24 & (135) \\
\hline & hypertension & 33 & spirapril & ACE-inhibitor & 40 & $(136)$ \\
\hline & hypertension & 34 & amlodipine, olmesartan & Ca2+-channel blocker, ARB & 13 & (38) \\
\hline & hypertension & 35 & amlodipine, valsartan & Ca2+-channel blocker, ARB & 7 & (39) \\
\hline & hypertension & 36 & amlodipine, valsartan & Ca2+-channel blocker, ARB & 7 & $(137)$ \\
\hline & hypertension & 37 & amlodipine, hydrochlorothiazide & Ca2+-channel blocker, diuretic & 6 & $(40)$ \\
\hline & hypertension & 38 & candesartan & ARB & 9 & $(138)$ \\
\hline & hypertension & 39 & valsartan & ARB & 7 & $(44)$ \\
\hline & hypertension & 40 & valsartan & ARB & 7 & (139) \\
\hline & hypertension & 41 & aspirin & NSAID & 1 & $(140)$ \\
\hline $\begin{array}{l}\text { Myocardial } \\
\text { Injury }\end{array}$ & myocardial injury & 1 & clopidogrel & P2Y12 inhibitor & 8 & $(141)$ \\
\hline & cardiovascular thromboembolism & 2 & rivaroxaban & factorXa inhibitor & 7 & $(142)$ \\
\hline & myocardial injury & 3 & aortic valve replacement & surgery & na & $(60)$ \\
\hline & myocardial injury & 4 & clopidogrel & P2Y12 inhibitor & 8 & (143) \\
\hline Other & GERD & 1 & omeprazole & PPI & 0.5 & $(14)$ \\
\hline & cognition & 2 & dextromethamphetamine & stimulant & 4.5 & $(144)$ \\
\hline & COPD & 3 & tiotropium & anticholinergic & 48 & $(145)$ \\
\hline & GERD & 4 & rabeprazole & PPI & 1.5 & $(146)$ \\
\hline & epilepsy & 5 & phenytoin, carbamazepine & anticonvulsant & 12 & $(147)$ \\
\hline & hypothyroidism & 6 & levothyroxine & hormone & 48 & (148) \\
\hline & high-risk pregnancy & 7 & aspirin & NSAID & 1 & $(149)$ \\
\hline & diabetes & 8 & lixisenatide & GLP-1 receptor agonist & 3 & $(150)$ \\
\hline & influenza & 9 & influenza vaccination & vaccine & na & $(151)$ \\
\hline & viral infection & 10 & liver transplant & surgery & na & (152) \\
\hline
\end{tabular}

Table S1. Details for each trial and reference. *Half-lives from DrugBank 5.0 (153), FDA-label information, or research publications. For drug combinations, the shortest-acting agent in the combination is reported in this table and in Fig 1.

Abbreviations. antihistH1 (antihistamine H1 antagonist); ARB (angiotensin II receptor blocker); PDEinhib (phosphodiesterase inhibitor); CT (chemotherapy); RT (radiotherapy); PPI (proton pump inhibitor); NSAID (nonsteroidal anti-inflammatory drug); L-OHP (oxaliplatin); RA (rheumatoid arthritis); OA (osteoarthritis); 5-FU (5-fluorouracil): FA (folinic acid); DOC (docetaxel); DDP (cisplatin); NSCLC (non small cell lung cancer); GM-CSF (granulocyte macrophage colony stimulating factor); NPC (nasopharyngeal carcinoma); HCC (hepatocellular carcinoma); GERD (gastroesophageal reflux disease); COPD (chronic obstructive pulmonary disease); GLP-1 (glucagon-like peptide 1) 


\section{Funding}

This work is supported by Cincinnati Children's Hospital Medical Center (DFS and JBH). JBH is supported by the National Institute of Neurological Disorders and Stroke (2R01NS054794 to JBH and Andrew Liu; and 1R21NS101983 to Tom Kilduff and JBH), the National Heart, Lung, and Blood Institute (R01HL138551 to Eric Bittman and JBH), and National Human Genome Research Institute (2R01HG005220 to Rafa Irizarry and JBH). In addition, GAF is supported in part by a MERIT award from the American Heart Association and a grant from the Volkswagen Foundation. GAF is a Senior Advisor to Calico Laboratories and has also received consulting fees from Amgen, Tremeau Pharmaceuticals and Heron Therapeutics.

\section{Author contributions}

M.D.R. and J.B.H. designed research; M.D.R. and D.F.S. performed research; M.D.R, D.F.S., G.A.F., and J.B.H. wrote the paper.

\section{Competing interests}

None. 
1. R. Zhang, N. F. Lahens, H. I. Ballance, M. E. Hughes, J. B. Hogenesch, A circadian gene expression atlas in mammals: implications for biology and medicine. Proc. Natl. Acad. Sci. U. S. A. 111, 16219-16224 (2014).

2. M. D. Ruben et al., A database of tissue-specific rhythmically expressed human genes has potential applications in circadian medicine. Sci. Transl. Med. 10 (2018), doi:10.1126/scitranslmed.aat8806.

3. D. S. Whittaker et al., Circadian-based Treatment Strategy Effective in the BACHD Mouse Model of Huntington's Disease. J. Biol. Rhythms, 748730418790401 (2018).

4. B. He, Z. Chen, Molecular Targets for Small-Molecule Modulators of Circadian Clocks. Curr. Drug Metab. 17, 503-512 (2016).

5. T. K. Tamai et al., Identification of circadian clock modulators from existing drugs. EMBO Mol. Med. 10 (2018), doi:10.15252/emmm.201708724.

6. HALBERG, F, Susceptibility to ouabain and physiologic circadian periodicity. Proc. Natl. Acad. Sci. U. S. A. 27, 139-143 (1959).

7. B. Hamprecht, C. Nüssler, F. Lynen, Rhythmic changes of hydroxymethylglutaryl coenzyme a reductase activity in livers of fed and fasted rats. FEBS Lett. 4, 117-121 (1969).

8. D. J. Shapiro, V. W. Rodwell, Diurnal variation and cholesterol regulation of hepatic HMG-CoA reductase activity. Biochem. Biophys. Res. Commun. 37, 867-872 (1969).

9. J. P. Caussanel et al., Phase I trial of 5-day continuous venous infusion of oxaliplatin at circadian rhythm-modulated rate compared with constant rate. J. Natl. Cancer Inst. 82, 1046-1050 (1990).

10. F. A. Lévi et al., Chronomodulated versus fixed-infusion-rate delivery of ambulatory chemotherapy with oxaliplatin, fluorouracil, and folinic acid (leucovorin) in patients with colorectal cancer metastases: a randomized multi-institutional trial. J. Natl. Cancer Inst. 86, 1608-1617 (1994).

11. F. Lévi, R. Zidani, J.-L. Misset, Randomised multicentre trial of chronotherapy with oxaliplatin, fluorouracil, and folinic acid in metastatic colorectal cancer. Lancet. $\mathbf{3 5 0}$, 681-686 (1997).

12. G. E. D'Alonzo, M. H. Smolensky, S. Feldman, Y. Gnosspelius, K. Karlsson, Bambuterol in the treatment of asthma. A placebo-controlled comparison of once-daily morning vs evening administration. Chest. 107, 406-412 (1995).

13. G. E. D'Alonzo et al., Twenty-four hour lung function in adult patients with asthma. Chronoptimized theophylline therapy once-daily dosing in the evening versus conventional twice-daily dosing. Am. Rev. Respir. Dis. 142, 84-90 (1990).

14. J. Hendel, L. Hendel, S. Aggestrup, Morning or evening dosage of omeprazole for gastro-oesophageal reflux disease? Aliment. Pharmacol. Ther. 9, 693-697 (1995). 
15. M. Middeke, M. Klüglich, H. Holzgreve, Chronopharmacology of captopril plus hydrochlorothiazide in hypertension: morning versus evening dosing. Chronobiol. Int. 8, 506-510 (1991).

16. P. Palatini, Can an angiotensin-converting enzyme inhibitor with a short half-life effectively lower blood pressure for 24 hours? Am. Heart J. 123, 1421-1425 (1992).

17. Top 200 Prescribed Medicines of 2018. ClinCalc (2018), (available at http://clincalc.com/DrugStats/Top200Drugs.aspx).

18. J. S. Takahashi, Transcriptional architecture of the mammalian circadian clock. Nat. Rev. Genet. 18, 164-179 (2017).

19. J. A. Mohawk, C. B. Green, J. S. Takahashi, Central and peripheral circadian clocks in mammals. Annu. Rev. Neurosci. 35, 445-462 (2012).

20. C. Skarke et al., A Pilot Characterization of the Human Chronobiome. Sci. Rep. 7, 17141 (2017).

21. G. Kaur, C. L. Phillips, K. Wong, A. J. McLachlan, B. Saini, Timing of Administration: For Commonly-Prescribed Medicines in Australia. Pharmaceutics. 8 (2016), doi:10.3390/pharmaceutics8020013.

22. L. S. Mure et al., Diurnal transcriptome atlas of a primate across major neural and peripheral tissues. Science, eaao0318 (2018).

23. G. K. Paschos, J. E. Baggs, J. B. Hogenesch, G. A. FitzGerald, The role of clock genes in pharmacology. Annu. Rev. Pharmacol. Toxicol. 50, 187-214 (2010).

24. C. Winter et al., Chrono-pharmacological Targeting of the CCL2-CCR2 Axis Ameliorates Atherosclerosis. Cell Metab. 28, 175-182.e5 (2018).

25. D. Guan et al., Diet-Induced Circadian Enhancer Remodeling Synchronizes Opposing Hepatic Lipid Metabolic Processes. Cell. 0 (2018), doi:10.1016/j.cell.2018.06.031.

26. R. C. Anafi, L. J. Francey, J. B. Hogenesch, J. Kim, CYCLOPS reveals human transcriptional rhythms in health and disease. Proceedings of the National Academy of Sciences. 114, 5312-5317 (2017).

27. S. L. Zhang, Z. Yue, D. M. Arnold, G. Artiushin, A. Sehgal, A Circadian Clock in the Blood-Brain Barrier Regulates Xenobiotic Efflux. Cell. 173, 130-139.e10 (2018).

28. Y. Saito, S. Yoshida, N. Nakaya, Y. Hata, Y. Goto, Comparison between morning and evening doses of simvastatin in hyperlipidemic subjects. A double-blind comparative study. Arterioscler. Thromb. 11, 816-826 (1991).

29. T. M. Lund et al., Effect of morning versus evening intake of simvastatin on the serum cholesterol level in patients with coronary artery disease. Am. J. Cardiol. 90, 784-786 (2002).

30. A. Wallace, D. Chinn, G. Rubin, Taking simvastatin in the morning compared with in the 
evening: randomised controlled trial. BMJ. 327, 788 (2003).

31. T. Tharavanij et al., Lipid lowering efficacy between morning and evening simvastatin treatment: a randomized double-blind study. J. Med. Assoc. Thai. 93 Suppl 7, S109-13 (2010).

32. D. D. Cilla Jr, D. M. Gibson, L. R. Whitfield, A. J. Sedman, Pharmacodynamic effects and pharmacokinetics of atorvastatin after administration to normocholesterolemic subjects in the morning and evening. J. Clin. Pharmacol. 36, 604-609 (1996).

33. R. Plakogiannis, H. Cohen, D. Taft, Effects of morning versus evening administration of atorvastatin in patients with hyperlipidemia. Am. J. Health. Syst. Pharm. 62, 2491-2494 (2005).

34. S.-H. Kim et al., Efficacy and safety of morning versus evening dose of controlled-release simvastatin tablets in patients with hyperlipidemia: a randomized, double-blind, multicenter phase III trial. Clin. Ther. 35, 1350-60.e1 (2013).

35. Y. J. Yi et al., Comparison of the efficacy and safety profile of morning administration of controlled-release simvastatin versus evening administration of immediate-release simvastatin in chronic kidney disease patients with dyslipidemia. Clin. Ther. 36, 1182-1190 (2014).

36. T. Mengden, B. Binswanger, T. Spühler, B. Weisser, W. Vetter, The use of self-measured blood pressure determinations in assessing dynamics of drug compliance in a study with amlodipine once a day, morning versus evening. J. Hypertens. 11, 1403-1411 (1993).

37. G. Nold, G. Strobel, B. Lemmer, Morning versus evening amlodipine treatment: effect on circadian blood pressure profile in essential hypertensive patients. Blood Press. Monit. 3, 17-25 (1998).

38. A. Hoshino, T. Nakamura, H. Matsubara, The bedtime administration ameliorates blood pressure variability and reduces urinary albumin excretion in amlodipine-olmesartan combination therapy. Clin. Exp. Hypertens. 32, 416-422 (2010).

39. R. C. Hermida, D. E. Ayala, M. J. Fontao, A. Mojón, J. R. Fernández, Chronotherapy with valsartan/amlodipine fixed combination: improved blood pressure control of essential hypertension with bedtime dosing. Chronobiol. Int. 27, 1287-1303 (2010).

40. J. Zeng et al., Fixed-combination of amlodipine and diuretic chronotherapy in the treatment of essential hypertension: improved blood pressure control with bedtime dosing-a multicenter, open-label randomized study. Hypertens. Res. 34, 767-772 (2011).

41. G. E. Sander, C. Fernandez, T. D. Giles, Fixed-dose combination therapy of nebivolol and valsartan for the treatment of hypertension. Expert Rev. Cardiovasc. Ther. 14, 563-572 (2016).

42. R. C. Hermida et al., Administration time-dependent effects of valsartan on ambulatory blood pressure in hypertensive subjects. Hypertension. 42, 283-290 (2003). 
43. R. C. Hermida et al., Treatment of non-dipper hypertension with bedtime administration of valsartan. J. Hypertens. 23, 1913-1922 (2005).

44. C. Wang et al., Effect of valsartan with bedtime dosing on chronic kidney disease patients with nondipping blood pressure pattern. J. Clin. Hypertens. . 15, 48-54 (2013).

45. D. Mauvoisin et al., Circadian clock-dependent and -independent rhythmic proteomes implement distinct diurnal functions in mouse liver. Proc. Natl. Acad. Sci. U. S. A. 111, 167-172 (2014).

46. D. Feng, M. A. Lazar, Clocks, metabolism, and the epigenome. Mol. Cell. 47, 158-167 (2012).

47. S. Y. Krishnaiah et al., Clock Regulation of Metabolites Reveals Coupling between Transcription and Metabolism. Cell Metab. 25, 961-974.e4 (2017).

48. E. S. Arnardottir et al., Blood-gene expression reveals reduced circadian rhythmicity in individuals resistant to sleep deprivation. Sleep. 37, 1589-1600 (2014).

49. S. N. Archer et al., Mistimed sleep disrupts circadian regulation of the human transcriptome. Proc. Natl. Acad. Sci. U. S. A. 111, E682-91 (2014).

50. C. S. Möller-Levet et al., Effects of insufficient sleep on circadian rhythmicity and expression amplitude of the human blood transcriptome. Proc. Natl. Acad. Sci. U. S. A. 110, E1132-41 (2013).

51. M. Akashi et al., Noninvasive method for assessing the human circadian clock using hair follicle cells. Proc. Natl. Acad. Sci. U. S. A. 107, 15643-15648 (2010).

52. G. Wu et al., Population-level rhythms in human skin with implications for circadian medicine. Proc. Natl. Acad. Sci. U. S. A. 115, 12313-12318 (2018).

53. C.-Y. Chen et al., Effects of aging on circadian patterns of gene expression in the human prefrontal cortex. Proc. Natl. Acad. Sci. U. S. A. 113, 206-211 (2016).

54. H. Laverty et al., How can we improve our understanding of cardiovascular safety liabilities to develop safer medicines? Br. J. Pharmacol. 163, 675-693 (2011).

55. P. Bobin et al., Cyclic nucleotide phosphodiesterases in heart and vessels: A therapeutic perspective. Arch. Cardiovasc. Dis. 109, 431-443 (2016).

56. J. C. Shryock, L. Belardinelli, Adenosine and adenosine receptors in the cardiovascular system: biochemistry, physiology, and pharmacology. Am. J. Cardiol. 79, 2-10 (1997).

57. P. Mladěnka et al., Comprehensive review of cardiovascular toxicity of drugs and related agents. Med. Res. Rev. (2018), doi:10.1002/med.21476.

58. M. Goyal et al., Oral mucositis in morning vs. evening irradiated patients: a randomised prospective study. Int. J. Radiat. Biol. 85, 504-509 (2009).

59. S. Fournier et al., Relationship between time of day and periprocedural myocardial 
infarction after elective angioplasty. Chronobiol. Int. 31, 206-213 (2014).

60. D. Montaigne et al., Daytime variation of perioperative myocardial injury in cardiac surgery and its prevention by Rev-Erba antagonism: a single-centre propensity-matched cohort study and a randomised study. Lancet (2017), doi:10.1016/S0140-6736(17)32132-3.

61. M. H. Smolensky, R. C. Hermida, D. E. Ayala, R. Tiseo, F. Portaluppi, Administration-time-dependent effects of blood pressure-lowering medications: basis for the chronotherapy of hypertension. Blood Press. Monit. 15, 173-180 (2010).

62. R. H. Fagard et al., Daytime and nighttime blood pressure as predictors of death and cause-specific cardiovascular events in hypertension. Hypertension. 51, 55-61 (2008).

63. M. E. Hughes et al., Guidelines for Genome-Scale Analysis of Biological Rhythms. J. Biol. Rhythms. 32, 380-393 (2017).

64. Wu G, Ruben MD, Schmidt, RE, Francey LJ, Smith DF, Anaf RCi, Hughey JJ, Tassef Rf, Sherrill JD, Oblong JE, Mills KJ, Hogenesch JB, Population level rhythms in human skin: implications for circadian medicine. bioRxiv (2018), doi:10.1101/301820.

65. N. Wittenbrink et al., High-accuracy determination of internal circadian time from a single blood sample. J. Clin. Invest. (2018), doi:10.1172/JCI120874.

66. R. Braun et al., Universal method for robust detection of circadian state from gene expression. Proc. Natl. Acad. Sci. U. S. A. (2018), doi:10.1073/pnas.1800314115.

67. F. J. Alibhai et al., Short-term disruption of diurnal rhythms after murine myocardial infarction adversely affects long-term myocardial structure and function. Circ. Res. 114, 1713-1722 (2014).

68. K. M. Beauchemin, P. Hays, Dying in the dark: sunshine, gender and outcomes in myocardial infarction. J. R. Soc. Med. 91, 352-354 (1998).

69. S. Vásquez-Ruiz et al., A light/dark cycle in the NICU accelerates body weight gain and shortens time to discharge in preterm infants. Early Hum. Dev. 90, 535-540 (2014).

70. H. McKenna, G. T. J. van der Horst, I. Reiss, D. Martin, Clinical chronobiology: a timely consideration in critical care medicine. Crit. Care. 22, 124 (2018).

71. N. J. Schork, Personalized medicine: Time for one-person trials. Nature. 520, 609-611 (2015).

72. J. L. Campian et al., (American Society of Clinical Oncology, 2018), vol. 36, pp. e14035-e14035.

73. A. Reinberg, E. Sidi, Circadian changes in the inhibitory effects of an antihistaminic drug in man. J. Invest. Dermatol. 46, 415-419 (1966).

74. A. Reinberg, F. Levi, P. Guillet, J. T. Burke, A. Nicolai, Chronopharmacological study of antihistamines in man with special references to terfenadine. Eur. J. Clin. Pharmacol. 14, 
245-252 (1978).

75. R. Haye, K. Høye, O. Berg, S. Frønes, T. Odegård, Morning versus evening dosing of desloratadine in seasonal allergic rhinitis: a randomized controlled study [ISRCTN23032971]. Clin. Mol. Allergy. 3, 3 (2005).

76. J. R. Deandrade, J. N. Mccormick, A. G. Hill, SMALL DOSES OF PREDNISOLONE IN THE MANAGEMENT OF RHEUMATOID ARTHRITIS. Ann. Rheum. Dis. 23, 158-162 (1964).

77. I. C. Kowanko, R. Pownall, M. S. Knapp, A. J. Swannell, P. G. Mahoney, Circadian variations in the signs and symptoms of rheumatoid arthritis and in the therapeutic effectiveness of flurbiprofen at different times of day. Br. J. Clin. Pharmacol. 11, 477-484 (1981).

78. M. De Silva, A. Binder, B. L. Hazleman, The timing of prednisolone dosage and its effect on morning stiffness in rheumatoid arthritis. Ann. Rheum. Dis. 43, 790-793 (1984).

79. F. Levi, C. Le Louarn, A. Reinberg, Timing optimizes sustained-release indomethacin treatment of osteoarthritis. Clin. Pharmacol. Ther. 37, 77-84 (1985).

80. N. G. Arvidson, B. Gudbjörnsson, A. Larsson, R. Hällgren, The timing of glucocorticoid administration in rheumatoid arthritis. Ann. Rheum. Dis. 56, 27-31 (1997).

81. F. Buttgereit et al., Efficacy of modified-release versus standard prednisone to reduce duration of morning stiffness of the joints in rheumatoid arthritis (CAPRA-1): a double-blind, randomised controlled trial. Lancet. 371, 205-214 (2008).

82. H. To et al., Methotrexate chronotherapy is effective against rheumatoid arthritis. Chronobiol. Int. 28, 267-274 (2011).

83. P. J. Barnes, G. A. Fitzgerald, C. T. Dollery, Circadian variation in adrenergic responses in asthmatic subjects. Clin. Sci. . 62, 349-354 (1982).

84. M. H. Smolensky et al., Administration-time-dependency of the pharmacokinetic behavior and therapeutic effect of a once-a-day theophylline in asthmatic children. Chronobiol. Int. 4, 435-447 (1987).

85. R. Dahl, H. Harving, L. Säwedal, S. Anehus, Terbutaline sustained-release tablets in nocturnal asthma - a placebo-controlled comparison between a high and a low evening dose. Br. J. Dis. Chest. 82, 237-241 (1988).

86. C. Gaultier, A. Reinberg, Y. Motohashi, Circadian rhythm in total pulmonary resistance of asthmatic children. Effects of a beta-agonist agent. Chronobiol. Int. 5, 285-290 (1988).

87. J. F. Morrison, S. B. Pearson, H. G. Dean, Parasympathetic nervous system in nocturnal asthma. Br. Med. J. . 296, 1427-1429 (1988).

88. W. R. Beam, D. E. Weiner, R. J. Martin, Timing of prednisone and alterations of airways inflammation in nocturnal asthma. Am. Rev. Respir. Dis. 146, 1524-1530 (1992).

89. W. W. Storms et al., The effect of repeat action albuterol sulfate (Proventil Repetabs) in 
nocturnal symptoms of asthma. J. Asthma. 29, 209-216 (1992).

90. P. Faurschou, A. M. Engel, O. C. Haanaes, Salmeterol in two different doses in the treatment of nocturnal bronchial asthma poorly controlled by other therapies. Allergy. 49, 827-832 (1994).

91. N. Burioka et al., Alteration of the circadian rhythm in peak expiratory flow of nocturnal asthma following nighttime transdermal beta2-adrenoceptor agonist tulobuterol chronotherapy. Chronobiol. Int. 22, 383-390 (2005).

92. D. Dinçol et al., Prospective randomized comparison of morning versus night daily single subcutaneous administration of granulocyte-macrophage-colony stimulating factor in patients with soft tissue or bone sarcoma. Cancer. 88, 2033-2036 (2000).

93. S. Giacchetti et al., Phase III trial comparing 4-day chronomodulated therapy versus 2-day conventional delivery of fluorouracil, leucovorin, and oxaliplatin as first-line chemotherapy of metastatic colorectal cancer: the European Organisation for Research and Treatment of Cancer Chronotherapy Group. J. Clin. Oncol. 24, 3562-3569 (2006).

94. G. A. Bjarnason et al., Comparison of toxicity associated with early morning versus late afternoon radiotherapy in patients with head-and-neck cancer: a prospective randomized trial of the National Cancer Institute of Canada Clinical Trials Group (HN3). Int. J. Radiat. Oncol. Biol. Phys. 73, 166-172 (2009).

95. C. Qvortrup et al., A randomized study comparing short-time infusion of oxaliplatin in combination with capecitabine XELOX(30) and chronomodulated XELOX(30) as first-line therapy in patients with advanced colorectal cancer. Ann. Oncol. 21, 87-91 (2010).

96. P. Shukla et al., Circadian variation in radiation-induced intestinal mucositis in patients with cervical carcinoma. Cancer. 116, 2031-2035 (2010).

97. D. A. Rahn 3rd et al., Gamma knife radiosurgery for brain metastasis of nonsmall cell lung cancer: is there a difference in outcome between morning and afternoon treatment? Cancer. 117, 414-420 (2011).

98. S. N. Badiyan et al., Impact of time of day on outcomes after stereotactic radiosurgery for non-small cell lung cancer brain metastases. Cancer. 119, 3563-3569 (2013).

99. H.-X. Lin et al., Randomized study of sinusoidal chronomodulated versus flat intermittent induction chemotherapy with cisplatin and 5-fluorouracil followed by traditional radiotherapy for locoregionally advanced nasopharyngeal carcinoma. Chin. J. Cancer. 32, 502-511 (2013).

100. J. M. Noh et al., Comparison of acute skin reaction following morning versus late afternoon radiotherapy in patients with breast cancer who have undergone curative surgical resection. J. Radiat. Res. 55, 553-558 (2014).

101. J. Li, R. Chen, M. Ji, S.-L. Zou, L.-N. Zhu, Cisplatin-based chronotherapy for advanced non-small cell lung cancer patients: a randomized controlled study and its pharmacokinetics 
analysis. Cancer Chemother. Pharmacol. 76, 651-655 (2015).

102. Bi T. et al., [Phase II clinical trial of two different modes of administration of the induction chemotherapy for locally advanced nasopharyngeal carcinoma]. Zhonghua Zhong Liu Za Zhi. 37, 676-681 (2015).

103. F.-M. Hsu et al., Differences in toxicity and outcome associated with circadian variations between patients undergoing daytime and evening radiotherapy for prostate adenocarcinoma. Chronobiol. Int. 33, 210-219 (2016).

104. S. Chan et al., Could time of whole brain radiotherapy delivery impact overall survival in patients with multiple brain metastases? Ann. Palliat. Med. 5, 267-279 (2016).

105. S. Chan et al., Effects of circadian rhythms and treatment times on the response of radiotherapy for painful bone metastases. Ann. Palliat. Med. 6, 14-25 (2017).

106. Y. Tsuchiya et al., Influence of a dosing-time on toxicities induced by docetaxel, cisplatin and 5-fluorouracil in patients with oral squamous cell carcinoma; a cross-over pilot study. Chronobiol. Int. 35, 289-294 (2018).

107. P. X. Zhang et al., A randomized phase II trial of induction chemotherapy followed by cisplatin chronotherapy versus constant rate delivery combined with radiotherapy.

Chronobiol. Int. 35, 240-248 (2018).

108. M. Ozaydin et al., Effects of morning versus evening intake of atorvastatin on major cardiac event and restenosis rates in patients undergoing first elective percutaneous coronary intervention. Am. J. Cardiol. 97, 44-47 (2006).

109. H. S. Yoon et al., Comparison of effects of morning versus evening administration of ezetimibe/simvastatin on serum cholesterol in patients with primary hypercholesterolemia. Ann. Pharmacother. 45, 841-849 (2011).

110. B. Langner, B. Lemmer, Circadian changes in the pharmacokinetics and cardiovascular effects of oral propranolol in healthy subjects. Eur. J. Clin. Pharmacol. 33, 619-624 (1988).

111. J. A. Panza, S. E. Epstein, A. A. Quyyumi, Circadian variation in vascular tone and its relation to alpha-sympathetic vasoconstrictor activity. N. Engl. J. Med. 325, 986-990 (1991).

112. B. Meilhac et al., [Study of the influence of the time of administration on the antihypertensive effect and nitrendipine tolerance in mild to moderate essential hypertensive patients. Value of ambulatory recording of blood pressure on 24 hours]. Therapie. 47, 205-210 (1992).

113. D. P. Myburgh, M. Verho, J. H. Botes, T. P. Erasmus, H. G. Luus, 24-hour blood pressure control with ramipril: comparison of once-daily morning and evening administration. Curr. Ther. Res. Clin. Exp. 56, 1298-1306 (1995).

114. R. Fogari, E. Malacco, F. Tettamanti, A. E. Gnemmi, M. Milani, Evening vs morning isradipine sustained release in essential hypertension: a double-blind study with $24 \mathrm{~h}$ 
ambulatory monitoring. Br. J. Clin. Pharmacol. 35, 51-54 (1993).

115. K. Witte et al., Cardiovascular effects, pharmacokinetics, and converting enzyme inhibition of enalapril after morning versus evening administration. Clin. Pharmacol. Ther. 54, 177-186 (1993).

116. P. Palatini et al., Effect of evening versus morning benazepril on 24-hour blood pressure: a comparative study with continuous intraarterial monitoring. Int. J. Clin. Pharmacol. Ther. Toxicol. 31, 295-300 (1993).

117. T. Umeda et al., Timing for administration of an antihypertensive drug in the treatment of essential hypertension. Hypertension. 23, I211-4 (1994).

118. P. Greminger, P. M. Suter, D. Holm, R. Kobelt, W. Vetter, Morning versus evening administration of nifedipine gastrointestinal therapeutic system in the management of essential hypertension. Clin. Investig. 72, 864-869 (1994).

119. F. Portaluppi, L. Vergnani, R. Manfredini, E. C. degli Uberti, C. Fersini, Time-dependent effect of isradipine on the nocturnal hypertension in chronic renal failure. Am. J. Hypertens. 8, 719-726 (1995).

120. T. Morgan, A. Anderson, E. Jones, The effect on $24 \mathrm{~h}$ blood pressure control of an angiotensin converting enzyme inhibitor (perindopril) administered in the morning or at night. J. Hypertens. 15, 205-211 (1997).

121. W. B. White et al., Differential effects of morning and evening dosing of nisoldipine ER on circadian blood pressure and heart rate. Am. J. Hypertens. 12, 806-814 (1999).

122. I. Kohno et al., Effect of imidapril in dipper and nondipper hypertensive patients: comparison between morning and evening administration. Chronobiol. Int. 17, 209-219 (2000).

123. Y.-G. Qiu, J.-Z. Chen, J.-H. Zhu, X.-Y. Yao, Differential effects of morning or evening dosing of amlodipine on circadian blood pressure and heart rate. Cardiovasc. Drugs Ther. 17, 335-341 (2003).

124. Y. Kitahara et al., Effect of morning and bedtime dosing with cilnidipine on blood pressure, heart rate, and sympathetic nervous activity in essential hypertensive patients. $J$. Cardiovasc. Pharmacol. 43, 68-73 (2004).

125. R. C. Hermida et al., Administration-time-dependent effects of doxazosin GITS on ambulatory blood pressure of hypertensive subjects. Chronobiol. Int. 21, 277-296 (2004).

126. T. Kuroda et al., Effects of bedtime vs. morning administration of the long-acting lipophilic angiotensin-converting enzyme inhibitor trandolapril on morning blood pressure in hypertensive patients. Hypertens. Res. 27, 15-20 (2004).

127. R. C. Hermida et al., Differing administration time-dependent effects of aspirin on blood pressure in dipper and non-dipper hypertensives. Hypertension. 46, 1060-1068 (2005).

128. R. C. Hermida et al., Administration time-dependent effects of valsartan on ambulatory 
blood pressure in elderly hypertensive subjects. Chronobiol. Int. 22, 755-776 (2005).

129. R. C. Hermida et al., in Journal of Hypertension (LIPPINCOTT WILLIAMS \& WILKINS 530 WALNUT ST, PHILADELPHIA, PA 19106-3621 USA, 2006), vol. 24, pp. S89-S89.

130. R. C. Hermida, D. E. Ayala, J. R. Fernández, C. Calvo, Comparison of the efficacy of morning versus evening administration of telmisartan in essential hypertension. Hypertension. 50, 715-722 (2007).

131. R. C. Hermida et al., Comparison of the effects on ambulatory blood pressure of awakening versus bedtime administration of torasemide in essential hypertension. Chronobiol. Int. 25, 950-970 (2008).

132. R. C. Hermida, D. E. Ayala, A. Mojón, J. R. Fernández, Ambulatory blood pressure control with bedtime aspirin administration in subjects with prehypertension. Am. J. Hypertens. 22, 896-903 (2009).

133. R. C. Hermida, D. E. Ayala, L. Chayan, A. Mojon, J. R. Fernandez, Administration-time-dependent effects of olmesartan on the ambulatory blood pressure of essential hypertension patients. Chronobiol. Int. 26, 61-79 (2009).

134. R. C. Hermida, D. E. Ayala, A. Mojón, J. R. Fernández, Chronotherapy with nifedipine GITS in hypertensive patients: improved efficacy and safety with bedtime dosing. Am. J. Hypertens. 21, 948-954 (2008).

135. R. C. Hermida, D. E. Ayala, Chronotherapy with the angiotensin-converting enzyme inhibitor ramipril in essential hypertension: improved blood pressure control with bedtime dosing. Hypertension. 54, 40-46 (2009).

136. R. C. Hermida et al., Administration-time-dependent effects of spirapril on ambulatory blood pressure in uncomplicated essential hypertension. Chronobiol. Int. 27, 560-574 (2010).

137. R. Asmar, P. Gosse, S. Queré, A. Achouba, Efficacy of morning and evening dosing of amlodipine/valsartan combination in hypertensive patients uncontrolled by $5 \mathrm{mg}$ of amlodipine. Blood Press. Monit. 16, 80-86 (2011).

138. K. Eguchi, M. Shimizu, S. Hoshide, K. Shimada, K. Kario, A bedtime dose of ARB was better than a morning dose in improving baroreflex sensitivity and urinary albumin excretion--the J-TOP study. Clin. Exp. Hypertens. 34, 488-492 (2012).

139. D. H. Zappe, N. Crikelair, A. Kandra, P. Palatini, Time of administration important? Morning versus evening dosing of valsartan. J. Hypertens. 33, 385-392 (2015).

140. T. N. Bonten et al., Time-dependent effects of aspirin on blood pressure and morning platelet reactivity: a randomized cross-over trial. Hypertension. 65, 743-750 (2015).

141. M. Kozinski et al., Diurnal variation in platelet inhibition by clopidogrel. Platelets. 22, 579-587 (2011).

142. S. Brunner-Ziegler et al., Comparison between the impact of morning and evening doses 
of rivaroxaban on the circadian endogenous coagulation rhythm in healthy subjects. $J$. Thromb. Haemost. 14, 316-323 (2016).

143. S. C. Gruber et al., Twenty-four-hour time dependency of clopidogrel effects in patients with acute coronary syndromes: The CiCAD-Study. Platelets, 1-7 (2018).

144. S. A. Shappell, G. L. Kearns, J. L. Valentine, D. F. Neri, C. A. DeJohn, Chronopharmacokinetics and chronopharmacodynamics of dextromethamphetamine in man. J. Clin. Pharmacol. 36, 1051-1063 (1996).

145. P. M. A. Calverley et al., Effect of tiotropium bromide on circadian variation in airflow limitation in chronic obstructive pulmonary disease. Thorax. 58, 855-860 (2003).

146. N. D. Pehlivanov, M. Olyaee, I. Sarosiek, R. W. McCallum, Comparison of morning and evening administration of rabeprazole for gastro-oesophageal reflux and nocturnal gastric acid breakthrough in patients with reflux disease: a double-blind, cross-over study. Aliment. Pharmacol. Ther. 18, 883-890 (2003).

147. R. Yegnanarayan, S. D. Mahesh, S. Sangle, Chronotherapeutic dose schedule of phenytoin and carbamazepine in epileptic patients. Chronobiol. Int. 23, 1035-1046 (2006).

148. R. Rajput, S. Chatterjee, M. Rajput, Can Levothyroxine Be Taken as Evening Dose? Comparative Evaluation of Morning versus Evening Dose of Levothyroxine in Treatment of Hypothyroidism. J. Thyroid Res. 2011, 505239 (2011).

149. D. E. Ayala, R. Ucieda, R. C. Hermida, Chronotherapy with low-dose aspirin for prevention of complications in pregnancy. Chronobiol. Int. 30, 260-279 (2013).

150. B. Ahrén, A. Leguizamo Dimas, P. Miossec, S. Saubadu, R. Aronson, Efficacy and safety of lixisenatide once-daily morning or evening injections in type 2 diabetes inadequately controlled on metformin (GetGoal-M). Diabetes Care. 36, 2543-2550 (2013).

151. J. E. Long et al., Morning vaccination enhances antibody response over afternoon vaccination: A cluster-randomised trial. Vaccine. 34, 2679-2685 (2016).

152. X. Zhuang, A. G. Lai, J. A. McKeating, I. Rowe, P. Balfe, Daytime variation in hepatitis C virus replication kinetics following liver transplant. Wellcome Open Res. 3, 96 (2018).

153. D. S. Wishart et al., DrugBank 5.0: a major update to the DrugBank database for 2018. Nucleic Acids Res. 46, D1074-D1082 (2017). 